\title{
Antimicrobial Properties of Microparticles Based on Carmellose Cross-Linked by $\mathrm{Cu}^{2+}$ Ions
}

\author{
Martina Kejdušová, ${ }^{1}$ Jakub Vysloužil, ${ }^{1}$ Kateřina Kubová, ${ }^{1}$ Vladimír Celer, ${ }^{2}$ \\ Magdaléna Krásna, ${ }^{2}$ Alena Pechová, ${ }^{3}$ Věra Vyskočilová, ${ }^{3}$ and Vratislav Košt'ál ${ }^{4}$ \\ ${ }^{1}$ Department of Pharmaceutics, Faculty of Pharmacy, University of Veterinary and Pharmaceutical Sciences Brno, \\ Palackého Trída 1/3, 61242 Brno, Czech Republic \\ ${ }^{2}$ Department of Infectious Diseases and Microbiology, Faculty of Veterinary Medicine, University of Veterinary and \\ Pharmaceutical Sciences Brno, Palackého 1/3, 61242 Brno, Czech Republic \\ ${ }^{3}$ Department of Biochemistry and Biophysics, Faculty of Veterinary Hygiene and Ecology, University of Veterinary and \\ Pharmaceutical Sciences Brno, Palackého 1/3, 61242 Brno, Czech Republic \\ ${ }^{4}$ Tescan, Libušina Tř́da 863/21, 62300 Brno-Kohoutovice, Czech Republic
}

Correspondence should be addressed to Kateřina Kubová; kubovak@vfu.cz

Received 16 September 2014; Accepted 14 November 2014

Academic Editor: Kin Tam

Copyright (C) 2015 Martina Kejdušová et al. This is an open access article distributed under the Creative Commons Attribution License, which permits unrestricted use, distribution, and reproduction in any medium, provided the original work is properly cited.

\begin{abstract}
Carmellose (CMC) is frequently used due to its high biocompatibility, biodegradability, and low immunogenicity for development of site-specific or controlled release drug delivery systems. In this experimental work, CMC dispersions in two different concentrations $(1 \%$ and $2 \%)$ cross-linked by copper (II) ions $\left(0.5,1,1.5\right.$, or $\left.2.0 \mathrm{M} \mathrm{CuCl}_{2}\right)$ were used to prepare microspheres with antimicrobial activity against Escherichia coli and Candida albicans, both frequently occurring pathogens which cause vaginal infections. The microparticles were prepared by an ionotropic gelation technique which offers the unique possibility to entrap divalent copper ions in a CMC structure and thus ensure their antibacterial activity. Prepared CMC microspheres exhibited sufficient sphericity. Both equivalent diameter and copper content were influenced by CMC concentration, and the molarity of copper (II) solution affected only the copper content results. Selected samples exhibited stable but $\mathrm{pH}$-responsive behaviour in environments which corresponded with natural ( $\mathrm{pH} 4.5)$ and inflamed ( $\mathrm{pH}$ 6.0) vaginal conditions. All the tested samples exhibited proven substantial antimicrobial activity against both Gram-negative bacteria Escherichia coli and yeast Candida albicans. Unexpectedly, a crucial parameter for microsphere antimicrobial activity was not found in the copper content but in the swelling capacity of the microparticles and in the degree of CMC surface shrinking.
\end{abstract}

\section{Introduction}

Carmellose (CMC) is a water-soluble anionic polysaccharide and semisynthetic derivative of cellulose [1] which has no harmful effects on human health. Its chains are linear $\beta(1 \rightarrow$ 4)-linked glucopyranose units. In addition, it contains a hydrophobic polysaccharide backbone and many hydrophilic carboxyl groups and, as a result, exhibits amphiphilic characteristics. CMC is used in a number of applications throughout the food, cosmetic, textile, paper, and ceramic industries as a viscosity modifier, thickener, emulsion stabilizer, and water retention and adhesive agent [2]. It also has tremendous potential for use in pharmaceutical products including sitespecific or controlled release drug delivery carrier matrices thanks to its high biocompatibility, biodegradability [3], and low immunogenicity [4]. In spite of the numerous positive properties of $\mathrm{CMC}$, it does not have any antimicrobial properties as it lacks antimicrobial functional groups [5]. To bestow CMC with antimicrobial properties, different possibilities have been proposed, such as (i) adding different antimicrobial agents, for example, potassium sorbate [6] or silver nitrate [7], (ii) grafting $\mathrm{CMC}$ with different antimicrobial substances, for example, guanidine hydrochloride [8], (iii) combining CMC with other polymers that exhibit antimicrobial properties, 
for example, carboxymethyl chitosan $[9,10]$, or (iv) preparing nanoparticles of certain metals, for example, with silver [7] or copper [11], and incorporating them into the CMC structure.

Copper is one of the most abundant trace elements found in the human body. It is an essential nutrient involved in catalyzing biochemical reactions. However, excessive copper levels can be toxic, mainly because they cause oxidative damage to the body. Copper can change its redox status by accepting and donating electrons, shifting between cuprous $\left(\mathrm{Cu}^{+}\right)$and cupric $\left(\mathrm{Cu}^{2+}\right)$ forms, and therefore participate in reactions that generate superoxide radicals and hydrogen peroxide, which are major reactive oxygen species in the body. That is why a systemic usage of copper is limited in the human body with exception of rheumatoid arthritis treatment [12-14]. New options for copper utilization can be found in its local effect via vaginal application of dosage forms based on copper ions for their strong antibacterial and spermicidal and/or spermiostatic effect. The vagina produces fluid at a rate of $3-4 \mathrm{~g} / 4 \mathrm{~h}$ [15] which can reduce the potent local toxic effect of the copper compounds. Mucus efficiently traps foreign particles and particulates by both steric and adhesive mechanisms, facilitating rapid clearance [16]. Daunter used copper ethylenediaminetetraacetic acid/Lascorbic acid as a fertilization-preventing agent that can be delivered via nonbiodegradable, polyurethane, or polyvinyl acetate vaginal discs [17].

An aqueous CMC solution can undergo a sol-gel transformation in the presence of cross-linking cations and thus allow for the creation of solid gel microparticles. This method is known as an ionotropic gelation technique and is based on the impact of physical (electrostatic) forces and polyelectrolyte complexation with the presence of polyvalent ions [18]. In general, divalent cations (e.g., $\mathrm{Ba}^{2+}, \mathrm{Sr}^{2+}, \mathrm{Cd}^{2+}, \mathrm{Co}^{2+}$, $\mathrm{Ca}^{2+}, \mathrm{Mn}^{2+}, \mathrm{Ni}^{2+}, \mathrm{Pb}^{2+}$, and $\mathrm{Zn}^{2+}$ ) are suitable cross-linking agents for this method [19]. Thus, ionotropic gelation offers a unique possibility to incorporate divalent copper ions into the CMC structure and form microspheres with potential antimicrobial properties.

The aim of the presented research was to prepare $\mathrm{Cu}^{2+}$ cross-linked CMC microspheres using external ionic gelation and assess their antimicrobial activity against Gram-negative Escherichia coli and Candida albicans yeast, both frequently occurring pathogens responsible for vaginal infections.

\section{Materials and Methods}

2.1. Materials. Blanose-carmellose (CMC) with a medium viscosity grade (1500-3100 $\mathrm{mPa} \cdot \mathrm{s}$ for $2 \%$ in water) and a DS of 1.2 was used as the polymer carrier (Ashland, Covington, USA), copper (II) chloride was used as a cross-linking agent (Sigma Aldrich, St. Louis, USA), and $\mathrm{HNO}_{3}(65 \% \mathrm{v} / \mathrm{v})$ and $\mathrm{H}_{2} \mathrm{O}_{2}(30 \% \mathrm{v} / \mathrm{v})$ used for the determination of copper content were purchased from Analytika (Prague, Czech Republic). Calibration solutions were prepared using a dilution of $1000 \mathrm{mg} / \mathrm{L}$ stock copper reference solvent (Analytika, Prague, Czech Republic). Deionised water with a resistivity of $18 \mathrm{M} \Omega$ was used for all necessary dilution.
TABLE 1: Variables during preparation of microparticles samples.

\begin{tabular}{lcc}
\hline Sample & $\begin{array}{c}\text { CMC } \\
\text { concentration (\%) }\end{array}$ & $\begin{array}{c}\text { Molarity of } \mathrm{CuCl}_{2} \\
\left(\mathrm{~mol} / \mathrm{dm}^{3}\right)\end{array}$ \\
\hline MP-1_0.5 & 1 & 0.5 \\
MP-1_1.0 & 1 & 1.0 \\
MP-1_1.5 & 1 & 1.5 \\
MP-1_2.0 & 1 & 2.0 \\
MP-2_0.5 & 2 & 0.5 \\
MP-2_1.0 & 2 & 1.0 \\
MP-2_1.5 & 2 & 1.5 \\
MP-2_2.0 & 2 & 2.0 \\
\hline
\end{tabular}

\subsection{Methods}

2.2.1. Microparticles Preparation. Copper cross-linked CMC microparticles were prepared by a method of external ionic gelation. CMC dispersions ( $1 \%$ and $2 \%$ ) were prepared by dispersing $1 \mathrm{~g}$ and $2 \mathrm{~g}$ of CMC in purified water, respectively. The dispersions were heated to $80^{\circ} \mathrm{C}$ to increase the rate of swelling. They were then homogenized using an Ultra-Turrax (T25 basic, IKA-Werke, Staufen, Germany) at 13,000 rpm for $5 \mathrm{~min}$. The volume of each dispersion was ultimately adjusted to $100 \mathrm{~mL}$ with purified water. The resulting dispersions were then extruded through a needle with an internal diameter of $0.4 \mathrm{~mm}$ at a dropping rate of $2.0 \mathrm{~mL} / \mathrm{min}$ into $50 \mathrm{~mL}$ of 0.5 , $1.0,1.5$, or $2.0 \mathrm{M} \mathrm{CuCl}_{2}$ aqueous solution, respectively. The distance between the edge of the needle and the surface of the solution was adjusted to $5.0 \mathrm{~cm}$. Microparticle formation was instantaneous and the particles were left in the cross-linking solution for 1 hour to harden while being gently mixed. The resulting beads were subsequently washed three times with purified water and dried at $25^{\circ} \mathrm{C}$ in a cabinet drier (HORO 048B, Dr. Hofmann GmbH, Ostfildern, Germany) for $24 \mathrm{hrs}$ before testing. Prepared samples were named in accordance with the type and values of the altered variables (CMC concentration and molarity of the cross-linking medium). Samples characteristics are shown in Table 1.

2.2.2. Viscosity Measurement. To investigate the influence of the viscosity on the characteristics of the prepared microparticles, rheological measurements of CMC dispersions were performed. Dispersions (1.0 and $2.0 \mathrm{wt} \%$ ) were prepared and then homogenized with Ultra-Turrax (T25 BASIC, IKAWerke GmbH \& Co. KG, Staufen, Germany) at 16,000 rpm. Dynamic viscosity was measured by a Brookfield DVII+Pro rotary viscometer (Brookfield Engineering, Middleboro, USA) and Rheocalc software (Brookfield Engineering, Middleboro, USA) at $37^{\circ} \mathrm{C}$ and $200 \mathrm{rpm}$. A small sample adapter was employed for this step. Each sample was measured three times and the results were expressed as mean values with standard deviations (SD).

2.2.3. Scanning Electron Microscopy. In order to observe microparticle morphology and surface topography, scanning electron microscopy (SEM) was employed. The samples were 
mounted directly onto the SEM sample holder using doublesided sticking tape and then coated with a $10 \mathrm{~nm}$ thick layer of Au. Images were taken using the MIRA3 scanning electron microscope (Tescan, Brno, Czech Republic) at an accelerating voltage of $5.0 \mathrm{kV}$.

2.2.4. Optical Microscope Analysis. Particle size of the copper microparticles was measured using a NIKON SMZ 1500 stereoscopic microscope (Nikon, Tokyo, Japan) equipped with a 72AUC02 USB camera (The Imaging Source, Bremen, Germany). Microparticles were visualized under $\times 15$ magnification. The obtained images of 200 randomly chosen microparticles were stored and subsequently processed using the NIS-Elements AR 4.0 computer software (Nikon, Tokyo, Japan).

Equivalent diameter (ED) and sphericity factor (SF) were calculated from the measured values and expressed as arithmetic mean \pm standard deviation.

2.2.5. Copper Content in Microparticles. The copper content in the prepared microparticles was determined by atomic absorption. To digest the microparticles, $6 \mathrm{~mL}$ of concentrated nitric acid $(65 \% \mathrm{v} / \mathrm{v})$ and $2 \mathrm{~mL}$ of hydrogen peroxide $(30 \% \mathrm{v} / \mathrm{v})$ were added to $10 \mathrm{mg}$ of every sample and placed in a TFM digestion vessel. The vessels were closed and placed into the segment and the content was mineralized using an Ethos SEL Microwave Labstation (Milestone, Italy) at $220^{\circ} \mathrm{C}$ for $35 \mathrm{~min}$, applying a maximal power of $1000 \mathrm{~W}$. The microwave programme was started by steadily increasing the temperature over $15 \mathrm{~min}$, followed by holding the temperature for an additional $20 \mathrm{~min}$. After cooling, each resulting solution was transferred to $50 \mathrm{~mL}$ glass flasks and filled to the mark with deionized water. Samples were diluted to $1: 19$ with deionized water prior to further analysis. Copper content was measured using air-acetylene flame atomization in a contrAA 700 atomic absorption spectrometer (Analytik Jena, Germany). All samples were measured in triplicate and the obtained values were processed by Aspect CS software, version 2.1 .

2.2.6. Swelling Capacity. To determine swelling capacity, a previously reported method was improved [20]. The test was performed in a medium that properly simulates vaginal conditions. $100 \mathrm{mg}$ of each sample was put into fine mesh baskets and immersed in a $\mathrm{pH} 4.5$ medium (natural vaginal environment- $6.80 \mathrm{~g}$ of potassium dihydrogen phosphate $\mathrm{R}$ in $1000.0 \mathrm{~mL}$ of water $\mathrm{R}$ ) and a $\mathrm{pH} 6.0$ medium (infected vaginal environment- $6.8 \mathrm{~g}$ of sodium dihydrogen phosphate $\mathrm{R}$ in $1000.0 \mathrm{~mL}$ of water $\mathrm{R}, \mathrm{pH}$ adjustment with strong sodium hydroxide solution $\mathrm{R}$ ). The baskets were pulled out at time intervals of $5,10,15,30$, and $45 \mathrm{~min}$ and $1,2,3,4,5$, and 6 hours after the first immersion, properly dried, and weighed. Swelling capacity was calculated using the following equation [21]:

$$
S_{\mathrm{SW}}=\left(\frac{W_{t}-W_{0}}{W_{0}}\right) \times 100(\%)
$$

$S_{\mathrm{SW}}$ is swelling capacity expressed as a percentage of weight addition, $W_{t}$ is the weight of a sample at the relevant time interval, and $W_{0}$ represents the initial weight of the sample. For each batch, the measurement was performed three times and results were expressed as mean values with standard deviations.

2.2.7. Antimicrobial Activity: Bacterial Strains and MIC Determination. E. coli (CCM 4517) was maintained in a blood agar. To determine minimal inhibition concentration (MIC), an overnight culture of $E$. coli cells was suspended in a fresh LB (Luria broth) medium and grown to $\mathrm{OD}_{600} 0.5$ at $37^{\circ} \mathrm{C}$ at a shaking speed of $250 \mathrm{rpm}$.

Candida albicans (CCM 8186) was maintained in an YNB (Yeast Nitrogen Base with ammonium sulfate) medium at $37^{\circ} \mathrm{C}$. For MIC determination, an overnight culture was suspended in a fresh YNB medium and grown to $\mathrm{OD}_{600} 0.5$ at $37^{\circ} \mathrm{C}$ at a shaking speed of $250 \mathrm{rpm}$.

A suitable amount of CMC microparticles was suspended in the growth media (LB medium for E. coli, YNB for C. albicans) to prepare a $10 \%$ suspension and incubated for $60 \mathrm{~min}$ at room temperature to release the copper into solution. Undissolved particles were then separated by centrifugation and discarded and atomic absorption was used to determine copper concentration. Twofold dilutions of copper suspension were prepared in appropriate mediums in a microtiter plate $(100 \mu \mathrm{L} /$ well in triplicate). Then, $10 \mathrm{e} 6$ cells (E. coli or C. albicans) were added to each well of the microtiter plate and incubated at $37^{\circ} \mathrm{C}$. To monitor cell growth, optical density was measured spectrophotometrically $\left(\mathrm{OD}_{600}\right)$ after $20 \mathrm{hrs}$ of incubation. The mean of the three wells was calculated to evaluate antimicrobial activity. Wells containing the E. coli or $C$. albicans without copper inhibition were included in triplicate in all tested plates as controls. The MIC value was expressed as the concentration of copper in a well showing at least a fourfold reduction of $\mathrm{OD}_{600}$ absorbance compared to each subsequent well.

\section{Results and Discussion}

The copper cross-linked carmellose microparticles were evaluated for particle size, sphericity factor, and copper content (Table 2). The equivalent diameter of the prepared particles ranged from $738.1 \pm 30.3$ to $1078 \pm 12.4 \mu \mathrm{m}$. It seems that particle size did not depend on the concentration of the $\mathrm{Cu}^{2+}$ hardening solution. However, it was observed that it did increase with increasing $\mathrm{CMC}$ concentration which can be attributed to the increased viscosity $[22,23]$. Viscosity of the $1 \% \mathrm{CMC}$ dispersion was found to be $162 \pm 0.21 \mathrm{mPa} \cdot \mathrm{s}$ and that of the $2 \% \mathrm{CMC}$ dispersion $766.67 \pm 0.47 \mathrm{mPa} \cdot \mathrm{s}$. A polymer dispersion with higher viscosity is more difficult to form into smaller droplets [24]; thus these dispersions yielded larger particles. Another influence on the particle size of microspheres could be seen in the degree of CMC chain shrinkage. Generally, particle size decreases inversely with the degree of shrinkage. It has been well documented that the degree of shrinkage is typically higher for beads prepared from a dispersion with lower polymer concentration $[25,26]$. 


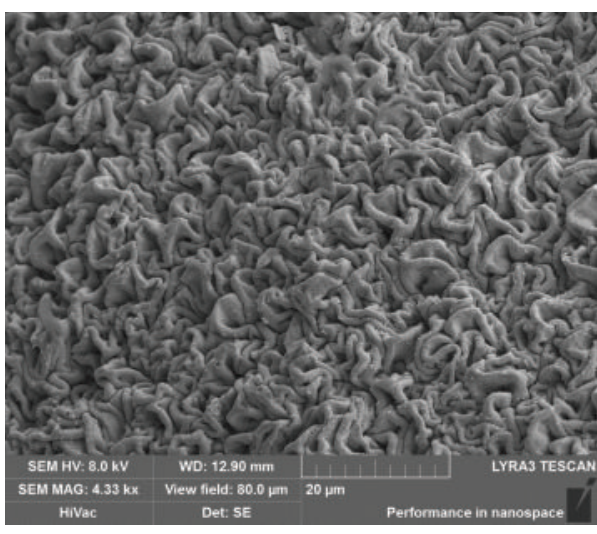

(a)

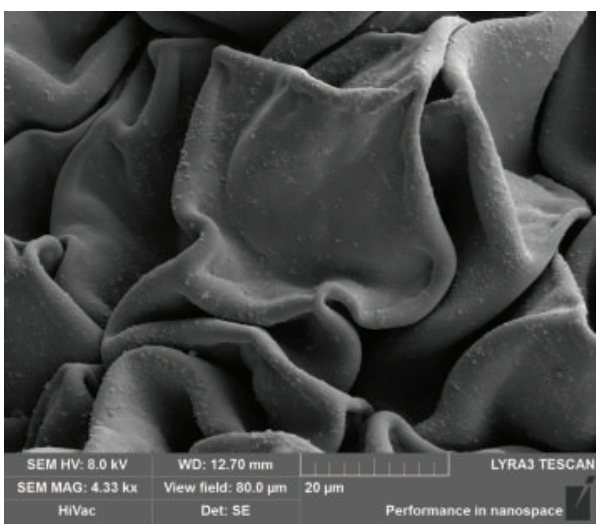

(c)

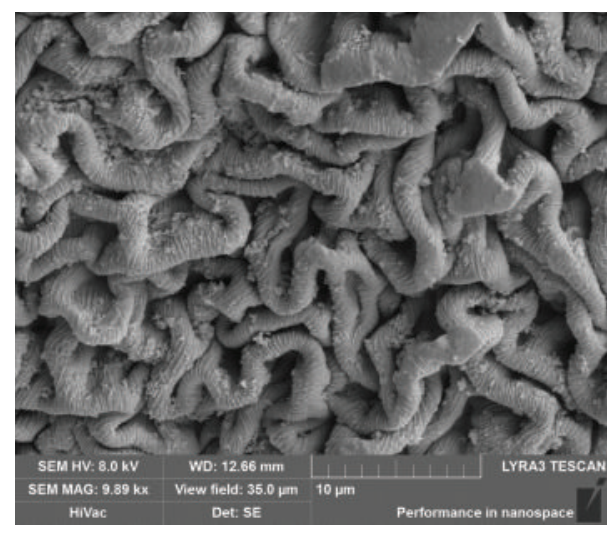

(b)

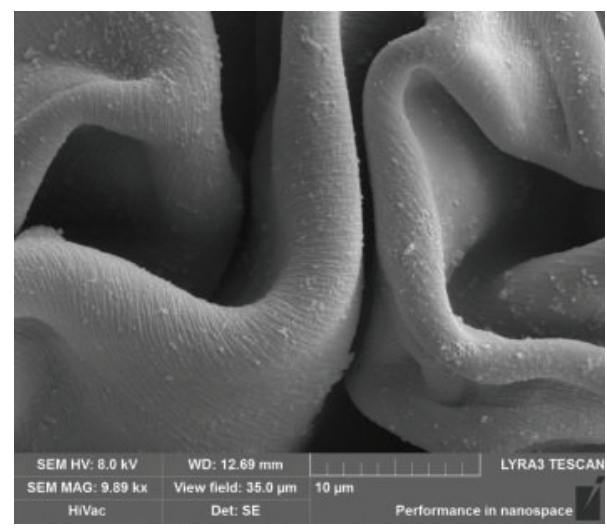

(d)

FIGURE 1: SEM photographs of surface topography of CMC microparticles: (a) MP-1_0.5 (magnification 4330x), (b) surface detail of MP-1_0.5 (magnification 9890x), (c) MP-2_0.5 (magnification 4330x), and (d) surface detail of MP-2_0.5 (magnification 9890x).

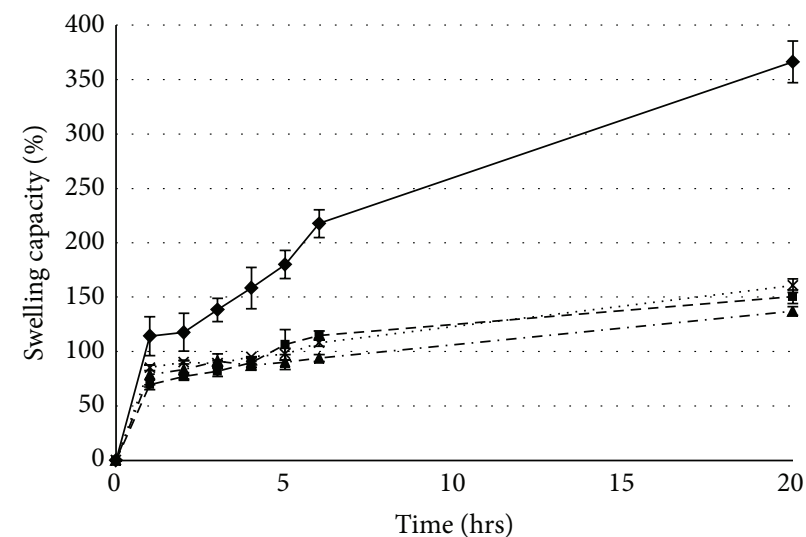

$\rightarrow-$ MP-1_0.5 (SD max. 24.11\%) - - - MP-1_1.0 (SD max. 12.53\%)

-. MP-2_0.5 (SD max. 14.10\%) … MP-2_1.0 (SD max. 6.30\%)

FIGURE 2: Degree of swelling in $\mathrm{Cu}^{2+}$ cross-linked microparticles at $\mathrm{pH} 4.5$.

A comparison of the microparticle surfaces (MP-1_0.5; ED = $775.7 \mu \mathrm{m}$ versus MP-2_0.5; ED = 1016.9) in Figure 1 confirms these findings. From these SEM photographs, it is evident that the degree of CMC shrinkage was significantly higher for the smaller 1\% CMC microspheres.

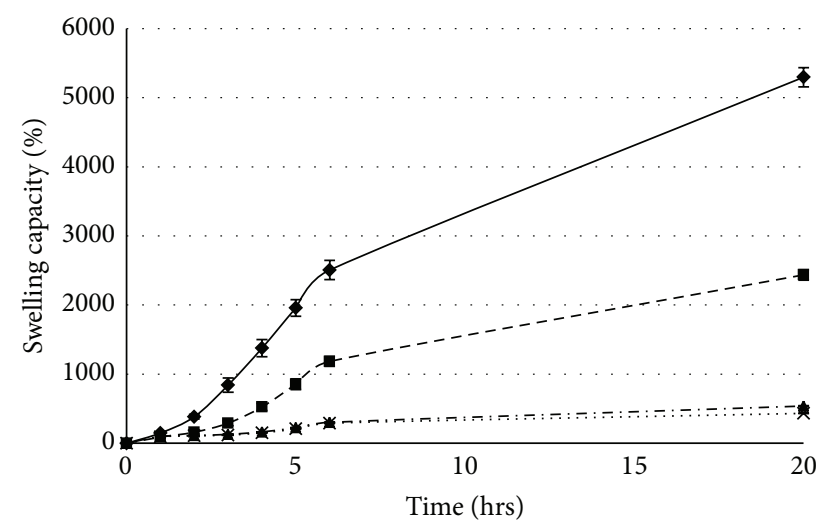

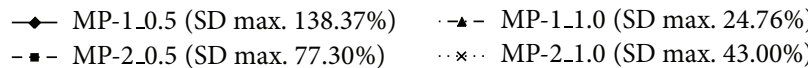

FIGURE 3: Degree of swelling in $\mathrm{Cu}^{2+}$ cross-linked microparticles at pH 6.0.

Prepared CMC microspheres exhibited sufficient sphericity, ranging from $0.850 \pm 0.067$ to $0.934 \pm 0.038$. Previous studies indicate that particles with this parameter value above 0.8 are considered to have good sphericity [27]. It can be observed from the results that the sphericity was not clearly 


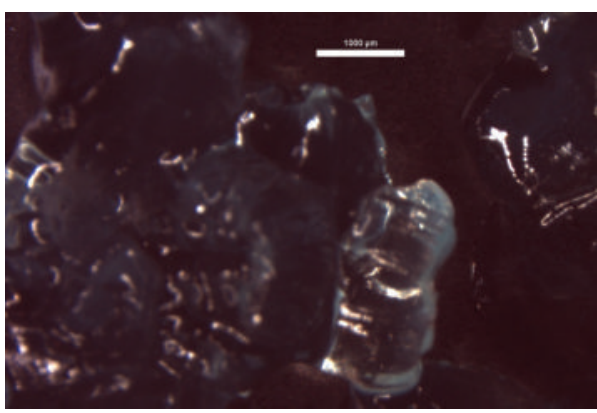

(a)

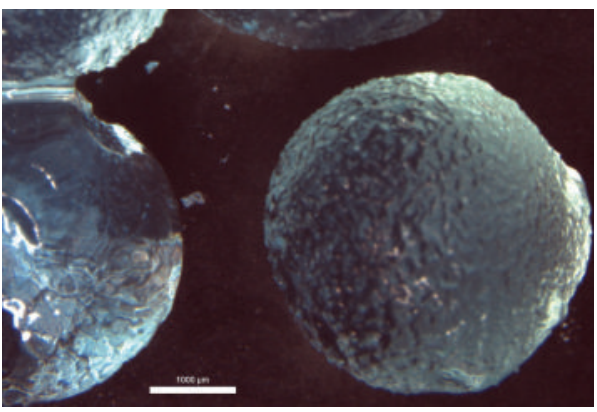

(c)

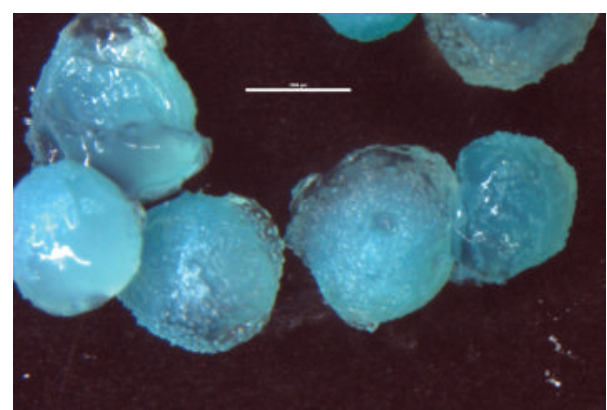

(b)

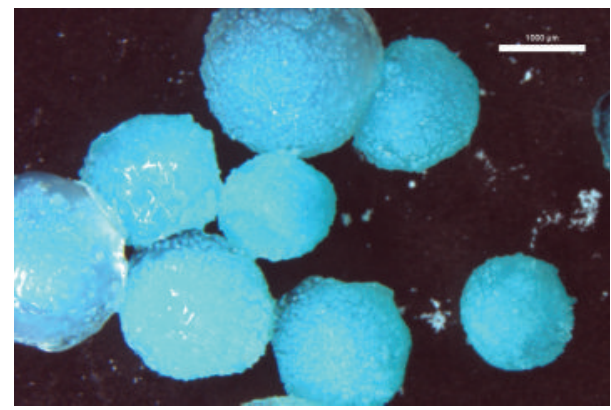

(d)

FIGURE 4: Optical microscope images of CMC particles after 20-hour swelling capacity test in pH 6.0 buffer; bars correspond to $1000 \mu \mathrm{m}$ : (a) MP-1_0.5, (b) MP-1_1.0, (c) MP-2_0.5, and (d) MP-2_1.0.

TABLE 2: Microparticle characteristics: equivalent diameter, sphericity factor, and copper content.

\begin{tabular}{|c|c|c|c|c|c|c|}
\hline Sample & $\mathrm{ED}(\mu \mathrm{m})$ & $\mathrm{SD}(\mu \mathrm{m})$ & SF & SD & Copper content $(\mathrm{g} / \mathrm{kg})$ & $\mathrm{SD}(\mathrm{g} / \mathrm{kg})$ \\
\hline MP-1_0.5 & 775.7 & 30.2 & 0.906 & 0.044 & 101.3 & 0.65 \\
\hline MP-1_1.0 & 888.5 & 58.4 & 0.934 & 0.038 & 143.6 & 2.31 \\
\hline MP-1_1.5 & 738.1 & 30.3 & 0.887 & 0.056 & 152.3 & 0.19 \\
\hline MP-1_2.0 & 798.6 & 87.9 & 0.855 & 0.059 & 173.0 & 2.15 \\
\hline MP-2_0.5 & 1016.9 & 22.8 & 0.891 & 0.040 & 143.6 & 0.26 \\
\hline MP-2_1.0 & 1078.0 & 12.4 & 0.886 & 0.071 & 164.7 & 0.40 \\
\hline MP-2_1.5 & 922.1 & 57.6 & 0.850 & 0.067 & 187.6 & 1.32 \\
\hline MP-2_2.0 & 933.6 & 38.6 & 0.874 & 0.057 & 200.3 & 1.03 \\
\hline
\end{tabular}

influenced by increasing the concentration of the hardening solution, but it was noticed that hardening solutions with lower molarity of $\mathrm{CuCl}_{2}$ ( 0.5 and $\left.1.0 \%\right)$ yielded microspheres with higher sphericity values. On the other hand, particle sphericity was lower in samples prepared with a higher polymer concentration, with the exception of samples MP1_2.0 and MP-2_2.0, which were prepared with $2 \mathrm{M}$ of $\mathrm{CuCl}_{2}$ hardening solution. Previously reported results confirmed that increasing the concentration of CMC solutions linearly increases the solution viscosity [28] and sphericity of particles. Our results generally coincide with findings that overly viscous polymer solutions ( $2 \%$ in our case) form less spherical, tail-shaped particles [29] and particles with a rough surface [30].

Table 2 also shows the results of atomic absorption analysis for copper content. Copper content in the prepared microparticles ranged from $101.3 \pm 0.65$ to $200.3 \pm 1.03 \mathrm{~g} / \mathrm{kg}$. It was observed that the content significantly increased with increases in hardening solution concentration as well as polymer concentration.

The samples of microspheres with the highest sphericity (MP-1_0.5, MP-1_1.0, MP-2_0.5, and MP-2_1.0), which is one the most important criteria for the preparation of particle systems, were then investigated for swelling capacity in phosphate buffers with $\mathrm{pH} 4.5$ [31] and $\mathrm{pH} 6.0$ [32], respectively, to simulate natural and inflamed vaginal conditions and to predict their behaviour on vaginal mucosa for a 20 -hour time interval (20-hour interval represents an estimated time of therapy). The obtained results can be seen in Figure 2 for $\mathrm{pH} 4.5$ and in Figure 3 for $\mathrm{pH}$ 6.0. Figure 4 shows images of microparticles after a 20-hour swelling capacity test in a pH 6.0 buffer. Generally, it was observed that the swelling capacity of all samples gradually increased during the test. Selected samples exhibited $\mathrm{pH}$-responsive behaviour which differed based on the tested environments; swelling was substantially higher at $\mathrm{pH} 6.0$ [33]. It is obvious from 


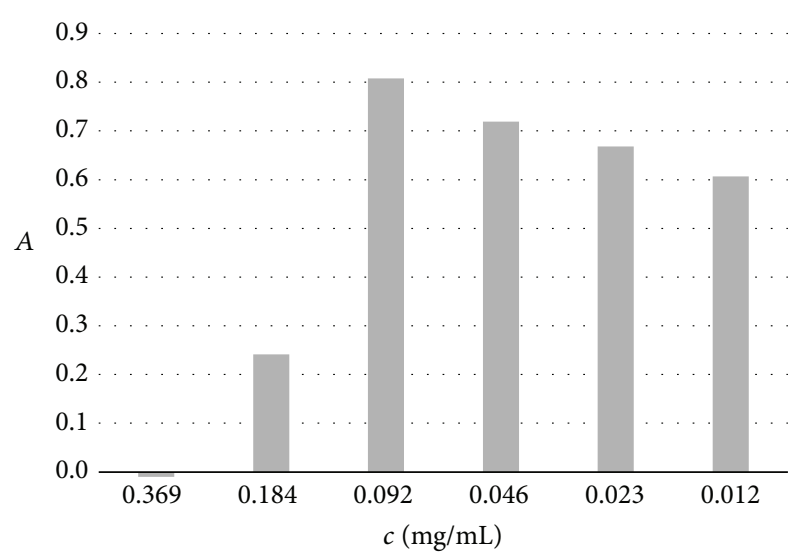

(a)

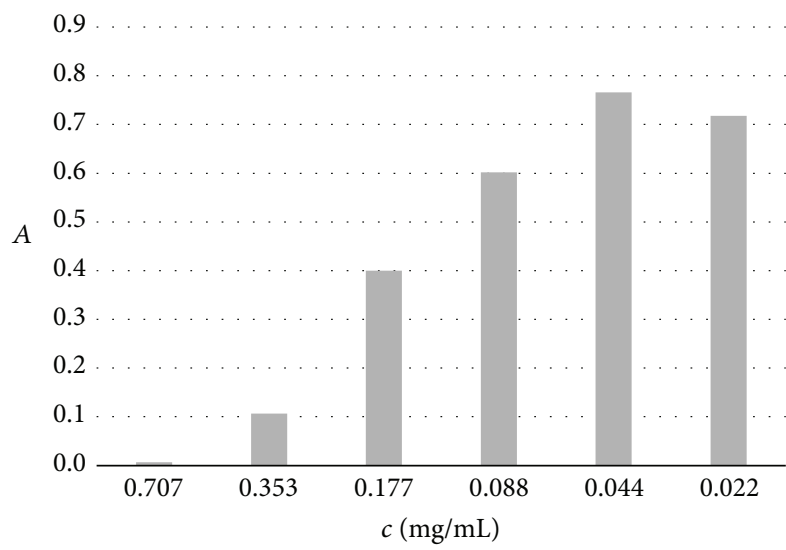

- $20 \mathrm{hrs}$

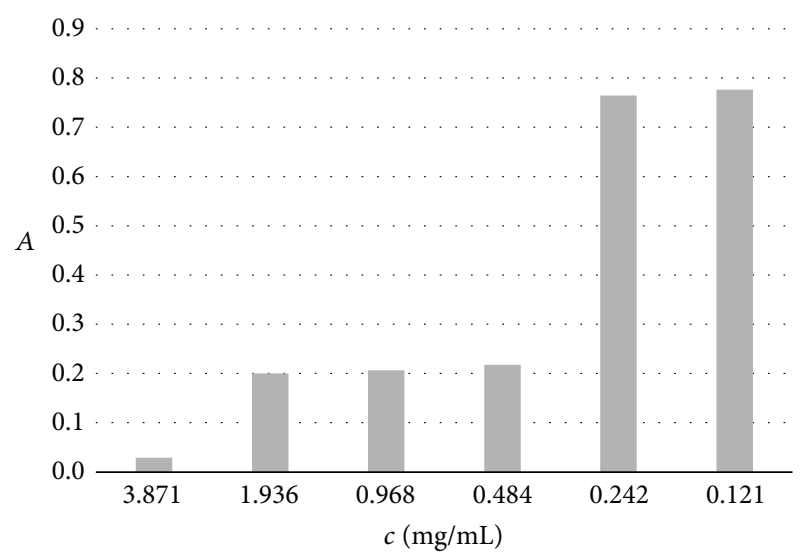

(b)

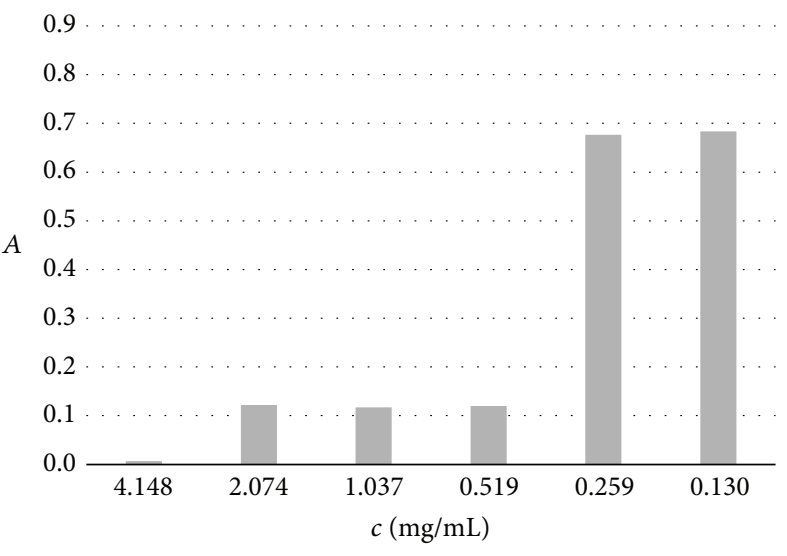

- $20 \mathrm{hrs}$

(c)

(d)

FIGURE 5: MIC results of CMC microparticles against Escherichia coli; (a) MP-1_0.5, (b) MP-1_1.0, (c) MP-2_0.5, and (d) MP-2_1.0.

Figures 2 and 3 that sample MP-1_0.5, prepared with a lessconcentrated hardening solution $(0.5 \mathrm{M})$ and a lower CMC concentration (1\%), had the highest swelling capacity at both $\mathrm{pH}$ values $(366.2 \%$ at $\mathrm{pH} 4.5$ after $20 \mathrm{hrs}, 5296.3 \%$ at $\mathrm{pH}$ 6.0 after $20 \mathrm{hrs}$ ). These values of formulation variables led to the creation of favourable conditions for water uptake into the microsphere matrix, resulting in the creation of an amorphous gel structure at pH 6.0 (see Figure 4(a)). Also, the enormous loss of the blue colour in comparison with sample MP-2_1.0 (Figure 4(d)) can be noticed, probably related to high water uptake and higher release of the copper ions which are responsible for the blue colour. This is uniquely in accordance with previously published data saying that increased polymer or hardening solution concentrations can significantly reduce water uptake due to the increased density of the polymer network [34]. At pH 6.0, sample MP-2_0.5 followed with swelling capacity of $2436.0 \%$ in 20 hrs. At pH 4.5 , however, its swelling was comparable with samples crosslinked with $1 \mathrm{M} \mathrm{CuCl}_{2}$, which exhibited a lower swelling capacity ranging from $137.2 \%$ to $160.7 \%$ after $20 \mathrm{hrs}$ at $\mathrm{pH} 4.5$ and $433.0 \%-539.1 \%$ at $\mathrm{pH} 6.0$ (results for $\mathrm{pH} 6.0$ are clearly evident in Figures 4(b) and 4(d)). No influence on swelling capacity as a result of particle size was observed.
The mechanism for the antibacterial activity of $\mathrm{Cu}^{+}$ ions is based on their energetically easier movement across a lipid bilayer and uptake by the cell, generating reactive oxygen species, leading to lipid peroxidation and protein oxidation [35]. The excess of copper causes a decrease in the membrane integrity of a microorganism, which causes the particular cell to leak nutritional elements, like potassium and glutamate, which lead to desiccation and, ultimately, cell death [36]. The antimicrobial activity of selected CMC microparticles cross-linked by $\mathrm{Cu}^{2+}$ was evaluated by MIC test using Gram-negative Escherichia coli and Candida albicans yeast (see Figures 5 and 6). The test expresses the minimum concentration of antimicrobial agent that inhibits the visible growth of microorganisms [37]. The test was triplicated. For E. coli, MIC values after $20 \mathrm{hrs}$ of incubation were $0.184,0.484,0.353$, and $0.519 \mathrm{mg} / \mathrm{mL}$ for samples MP1_0.5, MP-1_1.0, MP-2_0.5, and MP-2_1.0, respectively. MIC values for $C$. albicans were higher for the same samples: $0.740,1.639,0.598$, and $1.087 \mathrm{mg} / \mathrm{mL}$, respectively. Higher MIC values for C. albicans in comparison with the values for $E$. coli can be explained by the higher resistance of the yeast to the copper's antibacterial effect. Weissman et al. confirm this, reporting on the isolation of two genes involved 


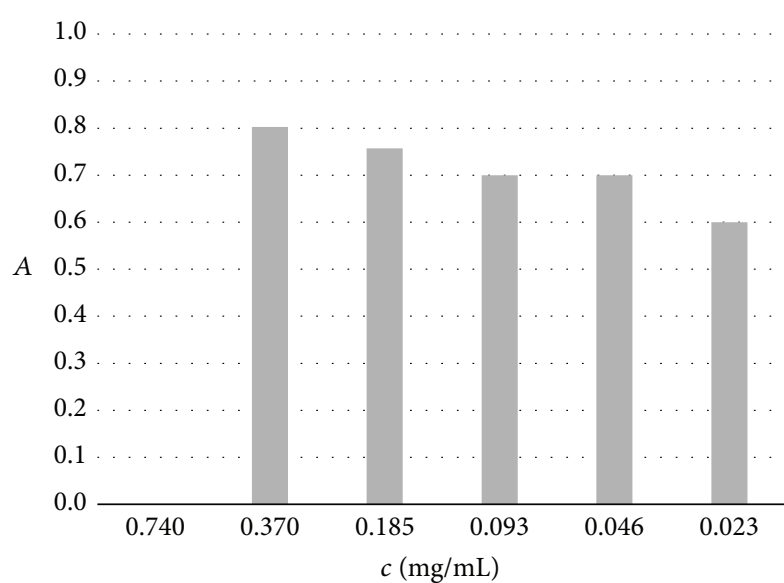

(a)

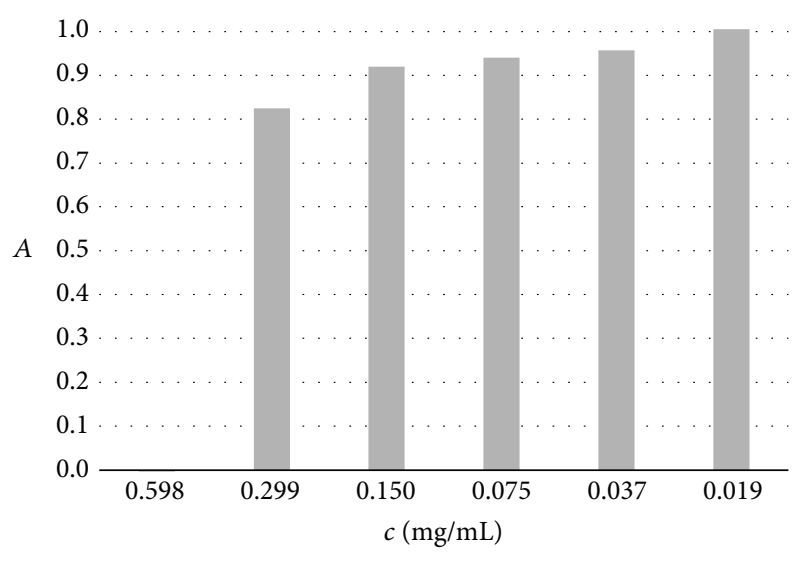

- $20 \mathrm{hrs}$

(c)

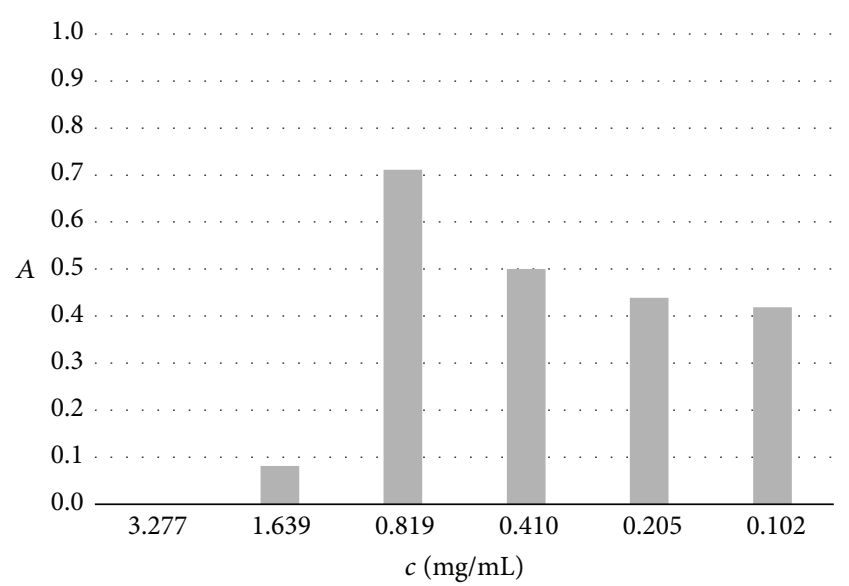

(b)

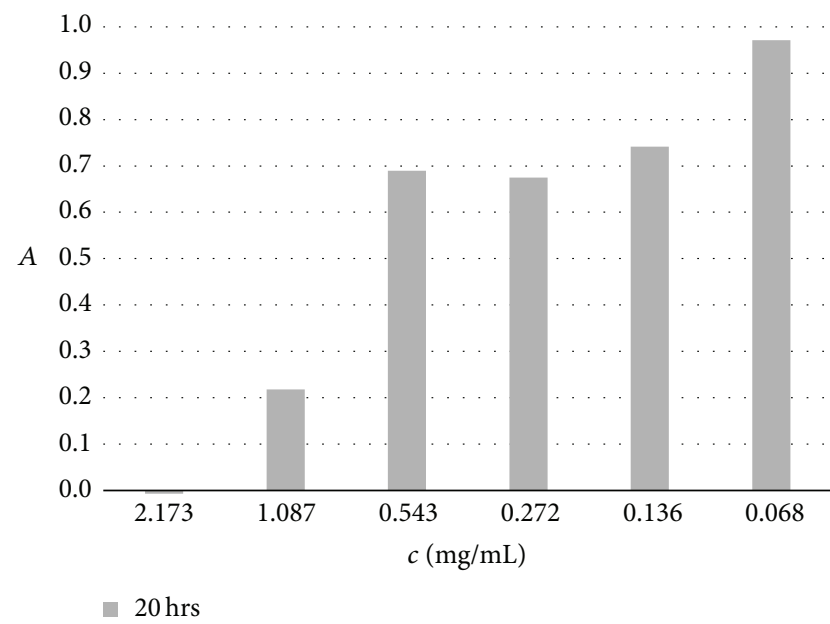

(d)

FIGURE 6: MIC results of CMC microparticles against Candida albicans; (a) MP-1_0.5, (b) MP-1_1.0, (c) MP-2_0.5, and (d) MP-2_1.0.

in copper detoxification in C. albicans: metallothionein, CaCUP1, and a copper-transporting P-type ATPase, CaCRP1 [38]. These two genes account for $C$. albicans's resistance to copper and consequently the vast differences in our results.

The obtained MIC values prove substantial antimicrobial activity against both microorganisms tested in this study and are in good agreement with copper MIC values against strains of $E$. coli and C. albicans described by different authors in other studies. Martínez Medina et al. reported MIC values for $\mathrm{Cu}$ (II) complexes of $0.375 \mathrm{mg} / \mathrm{mL}$ and $>1.5 \mathrm{mg} / \mathrm{mL}$ for $E$. coli and C. albicans, respectively [39]. Copper nanoparticles prepared by Zain et al. $(200 \mathrm{~nm})$ showed MIC values of $0.433 \mathrm{mg} / \mathrm{L}$ for E. coli [40], and those prepared by Ruparelia et al. $(9 \mathrm{~nm})$ showed MIC values of $0.280 \mathrm{mg} / \mathrm{mL}$ for $E$. coli [41].

Despite the lower content of copper in microspheres, the samples prepared using the less-concentrated $\mathrm{CuCl}_{2}$ $(0.5 \mathrm{M})$ solution-MP-1_0.5 and MP-2_0.5-exhibited lower MIC values and so better antibacterial activity against both tested pathogens in comparison with samples cross-linked in the more potent $1 \mathrm{M} \mathrm{CuCl}_{2}$ solution. These results confirmed the great influence of the microparticle swellability on MIC values. Both samples exhibited high swelling capacity at $\mathrm{pH}$ 6.0 (see Figure 3) and thus good conditions for the release of copper ions from particles ( $\mathrm{pH}$ of LB and YNB medium was also close to 6.0). Against E. coli, sample MP-1_0.5 was found to be the most effective, as it probably exhibited faster copper release. This could be a result of the higher cumulation of copper ions on more rougher surface (see Figures 1(a) and 1(b)) and also smaller particle size (see Table 2) and thus larger surface area [42]. These characteristics could promote faster swelling, leading to the creation of an amorphous structure during the 20-hour interval (Figure 4(a)). Against the more resistant $C$. albicans, however, the most effective sample was MP-2_0.5, exhibiting probably more uniform copper release due to the higher CMC concentraction (2\%), more uniform copper distribution in the microspheres, and larger particle size (see Table 2). This theory is also supported by the fact that the MP-2_0.5 microparticles maintained their shape-specific structure after $20 \mathrm{hrs}$ of swelling (Figure 4(c)). 


\section{Conclusion}

In this experimental work, CMC dispersions of two different concentrations ( $1 \%$ and $2 \%$ ) were cross-linked by copper (II) ions $\left(0.5,1,1.5\right.$, or $\left.2.0 \mathrm{M} \mathrm{CuCl}_{2}\right)$ to prepare microspheres with antimicrobial activity against frequently occurring vaginal pathogens Escherichia coli and Candida albicans. All tested samples exhibited stable but $\mathrm{pH}$ responsive behaviour in environments corresponding with natural and inflamed vaginal conditions and proved substantial antimicrobial activity against both pathogens. The most effective samples were those hardened in a less-concentrated $\mathrm{CuCl}_{2}(0.5 \mathrm{M})$ solution. Unexpectedly, a crucial parameter for microsphere antimicrobial activity was not found in the copper content but in the swelling capacity of the microparticles and in the degree of CMC surface shrinking. The sample prepared using a $1 \%$ CMC dispersion cross-linked by $0.5 \mathrm{M} \mathrm{CuCl}_{2}$ seemed to be the most suitable for potential vaginal use not only due to its antibacterial activity but also due to its gradual change to a nonspecific-shaped gel which is preferable when considering vaginal dosage forms.

\section{Conflict of Interests}

The authors declare that there is no conflict of interests regarding the publication of this paper.

\section{References}

[1] L. Fan, M. Peng, Z. Zhou et al., "Modification of carboxymethyl cellulose Grafted with collagen peptide and its antioxidant aktivity," Carbohydrate Polymers, vol. 112, pp. 32-38, 2014.

[2] N. Haleem, M. Arsah, M. Shahid, and A. M. Tahir, "Synthesis of carboxymethyl cellulose from waste of cotton ginning industry," Carbohydrate Polymers, vol. 113, pp. 249-255, 2014.

[3] J.-F. Su, Z. Huang, X.-Y. Yuan, X.-Y. Wang, and M. Li, "Structure and properties of carboxymethyl cellulose/soy protein isolate blend edible films crosslinked by Maillard reactions," Carbohydrate Polymers, vol. 79, no. 1, pp. 145-153, 2010.

[4] H. Kono, "Characterization and properties of carboxymethyl cellulose hydrogels crosslinked by polyethylene glycol," Carbohydrate Polymers, vol. 106, no. 1, pp. 84-93, 2014.

[5] E. A. Hassn, M. L. Hassan, N. C. Moorefield, and G. R. Newkome, "New supramolecular metallo-terpyridine carboxymethyl cellulose derivatives with antimicrobial properties," Carbohydrate Polymers, vol. 116, pp. 2-8, 2014.

[6] S. Sayanjali, B. Ghanbarzadeh, and S. Ghiassifar, "Evaluation of antimicrobial and physical properties of edible film based on carboxymethyl cellulose containing potassium sorbate on some mycotoxigenic Aspergillus species in fresh pistachios," LWTFood Science and Technology, vol. 44, no. 4, pp. 1133-1138, 2011.

[7] A. A. Hebeish, M. H. El-Rafie, F. A. Abdel-Mohdy, E. S. AbdelHalim, and H. E. Emam, "Carboxymethyl cellulose for green synthesis and stabilization of silver nanoparticles," Carbohydrate Polymers, vol. 82, no. 3, pp. 933-941, 2010.

[8] K. Liu, Y. Xu, X. Lin et al., "Synergistic effects of guanidinegrafted CMC on enhancing antimicrobial activity and dry strength of paper," Carbohydrate Polymers, vol. 110, pp. 382-387, 2014.
[9] L. Upadhyaya, J. Singh, V. Agarwal, and R. P. Tewari, "Biomedical applications of carboxymethyl chitosans," Carbohydrate Polymers, vol. 91, no. 1, pp. 452-466, 2013.

[10] A.-H. Yu, H.-Y. Hsieh, J.-C. Pang et al., "Active films from watersoluble chitosan/cellulose composites incorporating releasable caffeic acid for inhibition of lipid oxidation in fish oil emulsions," Food Hydrocolloids, vol. 32, no. 1, pp. 9-19, 2013.

[11] T. Zhong, G. S. Oporto, J. Jaczynski, A. T. Tesfai, and J. Armstrong, "Antimicrobial properties of the hybrid copper nanoparticles-carboxymethyl cellulose," Wood and Fiber Science, vol. 45, no. 2, pp. 215-222, 2013.

[12] G. E. Jackson, P. M. May, and D. R. Williams, "Metal-ligand complexes involved in rheumatoid arthritis-I: justifications for copper administration," Journal of Inorganic and Nuclear Chemistry, vol. 40, no. 6, pp. 1189-1194, 1978.

[13] O. A. El-Gammal, E. A. Elmorsy, and Y. E. Sherif, "Evaluation of the anti-inflammatory and analgesic effects of $\mathrm{Cu}(\mathrm{II})$ and $\mathrm{Zn}$ (II) complexes derived from 2-(naphthalen-1-yloxy)- $N^{\prime}$-(1(pyridin-2-1) ethylidene) acetohydrazide," Spectrochimica Acta Part A: Molecular and Biomolecular Spectroscopy, vol. 120, pp. 332-339, 2014.

[14] S. Odisitse and G. E. Jackson, "In vitro and in vivo studies of N,N/-bis[2(2-pyridyl)-methyl]pyridine-2,6-dicarboxamidecopper(II) and rheumatoid arthritis," Polyhedron, vol. 27, no. 1, pp. 453-464, 2008.

[15] A. Hussain and F. Ahsan, "The vagina as a route for systemic drug delivery," Journal of Controlled Release, vol. 103, no. 2, pp. 301-313, 2005.

[16] L. M. Ensign, T. E. Hoen, K. Maisel, R. A. Cone, and J. S. Hanes, "Enhanced vaginal drug delivery through the use of hypotonic formulations that induce fluid uptake," Biomaterials, vol. 34, no. 28, pp. 6922-6929, 2013.

[17] B. B. Saxena, M. Singh, R. M. Gospin, C. C. Chu, and W. J. Ledger, "Efficacy of nonhormonal vaginal contraceptives from a hydrogel delivery system," Contraception, vol. 70, no. 3, pp. 213219, 2004.

[18] M. L. González-Rodríguez, M. A. Holgado, C. SánchezLafuente, A. M. Rabasco, and A. Fini, "Alginate/chitosan particulate systems for sodium diclofenac release," International Journal of Pharmaceutics, vol. 232, no. 1-2, pp. 225-234, 2002.

[19] C. H. Goh, P. W. S. Heng, and L. W. Chan, "Alginates as a useful natural polymer for microencapsulation and therapeutic applications," Carbohydrate Polymers, vol. 88, no. 1, pp. 1-12, 2012.

[20] W.-C. Lin, D.-G. Yu, and M.-C. Yang, "pH-sensitive polyelectrolyte complex gel microspheres composed of chitosan/ sodium tripolyphosphate/dextran sulfate: swelling kinetics and drug delivery properties," Colloids and Surfaces B: Biointerfaces, vol. 44, no. 2-3, pp. 143-151, 2005.

[21] K. G. H. Desai and H. J. Park, "Preparation and characterization of drug-loaded chitosan-tripolyphosphate microspheres by spray drying," Drug Development Research, vol. 64, no. 2, pp. 114-128, 2005.

[22] K. M. Rao, B. Mallikarjuna, K. K. Rao, M. N. Prabhakar, K. C. Rao, and M. C. Subha, "Preparation and characterization of $\mathrm{pH}$ sensitive poly(vinyl alcohol)/sodium carboxymethyl cellulose IPN microspheres for in vitro release studies of an anti-cancer drug," Polymer Bulletin, vol. 68, no. 7, pp. 1905-1919, 2012.

[23] M. A. Saleem, Y. D. Murali, M. D. Naheed, P. Jaydeep, and M. Dhaval, "Prepapation and evaluation of valsartan loaded hydrogel beads," International Research Journal of Pharmacy, vol. 3, no. 6, pp. 80-85, 2012. 
[24] Y. Y. Yang, J. P. Wan, T. S. Chung, P. K. Pallathadka, S. Ng, and J. Heller, "POE-PEG-POE triblock copolymeric microspheres containing protein. I. Preparation and characterization," Journal of Controlled Release, vol. 75, no. 1-2, pp. 115-128, 2001.

[25] H. Brandenberger and F. Widmer, "A new multinozzle encapsulation/immobilisation system to produce uniform beads of alginate," Journal of Biotechnology, vol. 63, no. 1, pp. 73-80, 1998.

[26] E.-S. Chan, B.-B. Lee, P. Ravindra, and D. Poncelet, "Prediction models for shape and size of ca-alginate macrobeads produced through extrusion-dripping method," Journal of Colloid and Interface Science, vol. 338, no. 1, pp. 63-72, 2009.

[27] P. B. Deasy and M. F. L. Law, "Use of extrusion-spheronization to develop an improved oral dosage form of indomethacin," International Journal of Pharmaceutics, vol. 148, no. 2, pp. 201209, 1997.

[28] X. H. Yang and W. L. Zhu, "Viscosity properties of sodium carboxymethylcellulose solutions," Cellulose, vol. 14, no. 5, pp. 409-417, 2007.

[29] E.-S. Chan, "Preparation of Ca-alginate beads containing high oil content: influence of process variables on encapsulation efficiency and bead properties," Carbohydrate Polymers, vol. 84, no. 4, pp. 1267-1275, 2011.

[30] M. S. Kim, S. J. Park, B. K. Gu, and C.-H. Kim, "Ionically crosslinked alginate-carboxymethyl cellulose beads for the delivery of protein therapeutics," Applied Surface Science, vol. 262, pp. 28-33, 2012.

[31] C. Valenta, "The use of mucoadhesive polymers in vaginal delivery," Advanced Drug Delivery Reviews, vol. 57, no. 11, pp. 1692-1712, 2005.

[32] S. F. Borges, J. G. L. Silva, and P. C. M. Teixeira, "Survival and biofilm formation of Listeria monocytogenes in simulated vaginal fluid: influence of $\mathrm{pH}$ and strain origin," FEMS Immunology and Medical Microbiology, vol. 62, no. 3, pp. 315-320, 2011.

[33] R. Barbucci, A. Magnani, and M. Consumi, "Swelling behavior of carboxymethylcellulose hydrogels in relation to crosslinking, pH, and charge density," Macromolecules, vol. 33, no. 20, pp. 7475-7480, 2000.

[34] J. Berger, M. Reist, J. M. Mayer, O. Felt, N. A. Peppas, and R. Gurny, "Structure and interactions in covalently and ionically crosslinked chitosan hydrogels for biomedical applications," European Journal of Pharmaceutics and Biopharmaceutics, vol. 57, no. 1, pp. 19-34, 2004.

[35] U. Bogdanović, V. Lazić, V. Vodnik, M. Budimir, Z. Marković, and S. Dimitrijević, "Copper nanoparticles with high antimicrobial activity," Materials Letters, vol. 128, pp. 75-78, 2014.

[36] J. Konieczny and Z. Rdzawski, "Antibacterial properties of copper and its alloys," Archives of Materials Science and Engineering, vol. 56, no. 2, pp. 53-60, 2012.

[37] S. M. Magaña, P. Quintana, D. H. Aguilar et al., "Antibacterial activity of montmorillonites modified with silver," Journal of Molecular Catalysis A: Chemical, vol. 281, no. 1-2, pp. 192-199, 2008.

[38] Z. Weissman, I. Berdicevsky, B.-Z. Cavari, and D. Kornitzer, "The high copper tolerance of Candida albicans is mediated by a P-type ATPase," Proceedings of the National Academy of Sciences of the United States of America, vol. 97, no. 7, pp. 3520-3525, 2000.

[39] J. J. Martínez Medina, M. S. Islas, L. L. López Tévez, E. G. Ferrer, N. B. Okulik, and P. A. M. Williams, "Copper(II) complexes with cyanoguanidine and o-phenanthroline: theoretical studies, in vitro antimicrobial activity and alkaline phosphatase inhibitory effect," Journal of Molecular Structure, vol. 1058, no. 1, pp. 298-307, 2014.

[40] N. M. Zain, A. G. F. Stapley, and G. Shama, "Green synthesis of silver and copper nanoparticles using ascorbic acid and chitosan for antimicrobial applications," Carbohydrate Polymers, vol. 112, pp. 195-202, 2014.

[41] J. P. Ruparelia, A. K. Chatterjee, S. P. Duttagupta, and S. Mukherji, "Strain specificity in antimicrobial activity of silver and copper nanoparticles," Acta Biomaterialia, vol. 4, no. 3, pp. 707-716, 2008.

[42] J. Zhao, H. J. Feng, H. Q. Tang, and J. H. Zheng, "Bactericidal and corrosive properties of silver implanted TiN thin films coated on AISI317 stainless steel," Surface and Coatings Technology, vol. 201, no. 9-11, pp. 5676-5679, 2007. 

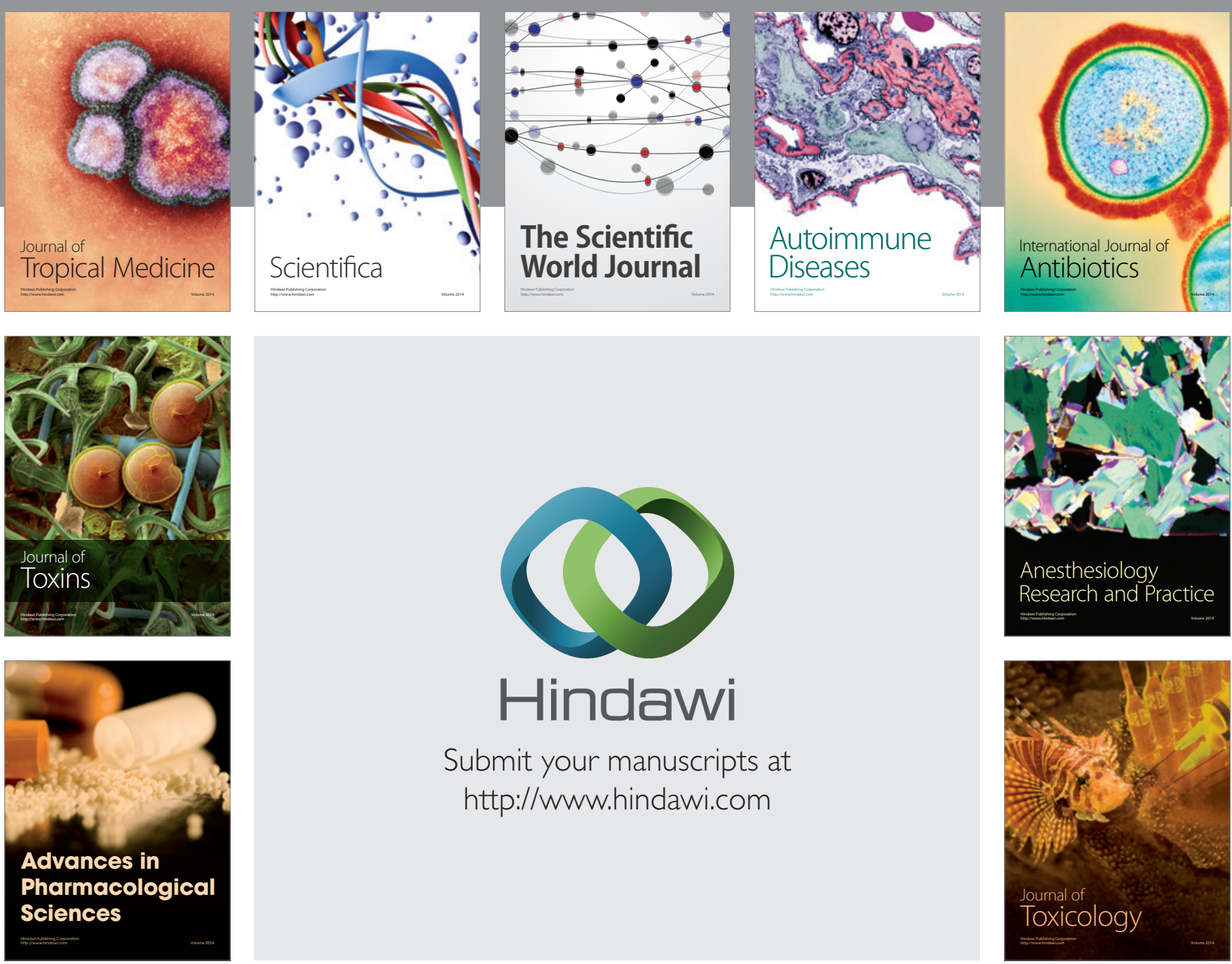

\section{Hindawi}

Submit your manuscripts at

http://www.hindawi.com
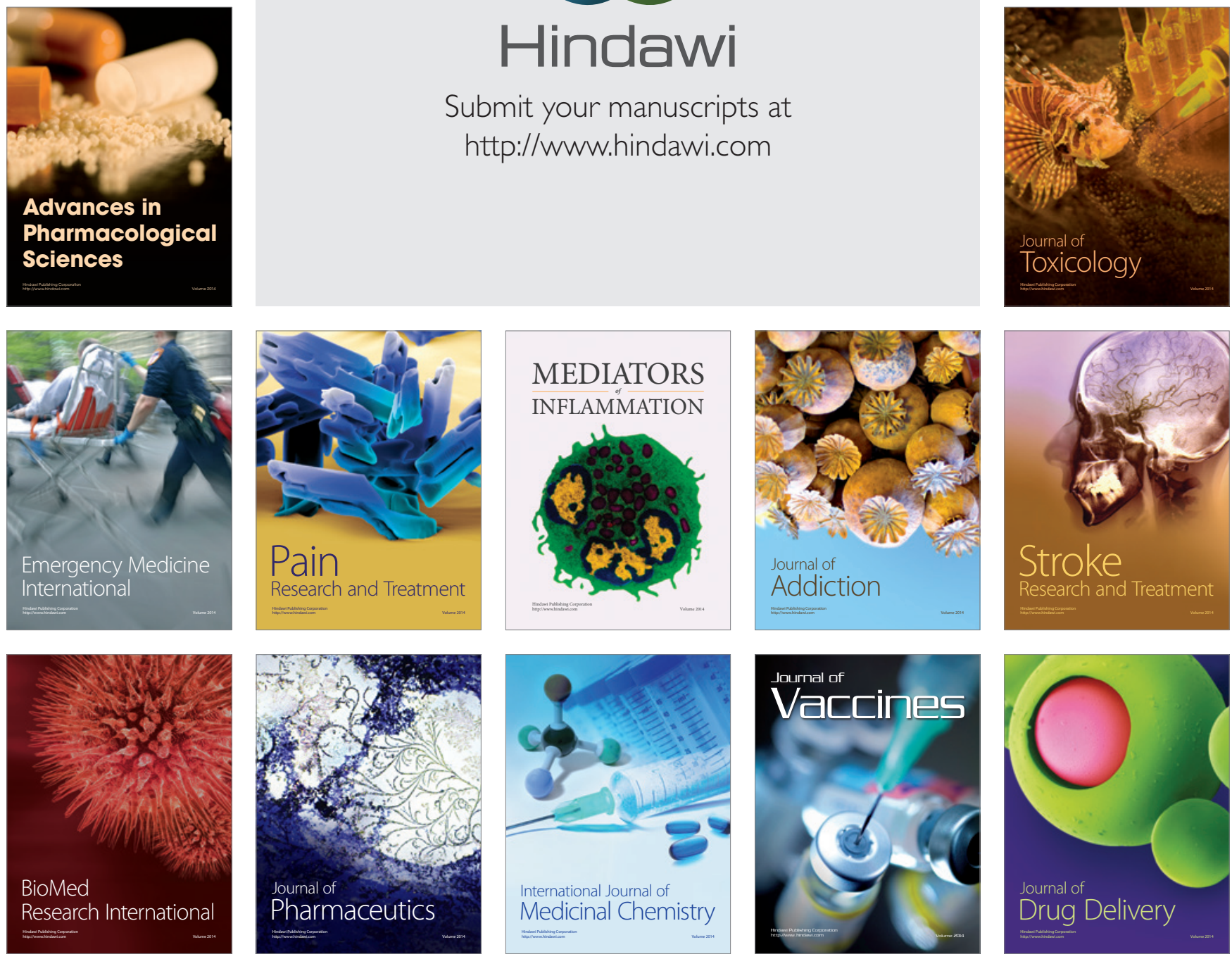